\title{
LA GARANTÍA DE LA UNIDAD Y LA ESTABILIDAD FEDERAL: ALGUNOS MODELOS EUROPEOS (PORTUGAL, ITALIA, AUSTRIA, SUIZA Y BÉLGICA)
}

\author{
Federal unity and stability guarantee: some European \\ models (Portugal, Italy, Austria, Switzerland and Belgium)
}

\author{
PATRICIA RODRÍGUEZ-PATRÓN \\ Universidad Autónoma de Madrid \\ patricia.rodriguez@uam.es
}

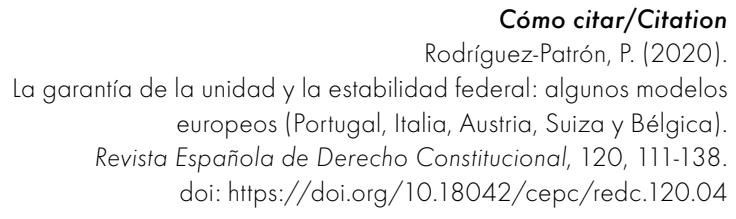

Resumen

El presente trabajo trata de mostrar los instrumentos con que cuentan distintos Estados de nuestro entorno jurídico para remediar situaciones de grave incumplimiento por parte de los Estados miembros o regiones de sus deberes constitucionales que puedan poner en peligro a la federación respectiva. Todo ello precedido de una sintética exposición del contexto territorial fijado por cada una de las constituciones de los países estudiados, dentro del cual los citados instrumentos cobran su verdadero sentido. En concreto, se muestran los casos de Portugal, Italia, Austria, Suiza y Bélgica, pudiéndose observar con ellos la diversidad de técnicas, así como de órganos implicados en la coerción federal, que encuentran su explicación en las especiales características de cada ordenamiento. Un caso particular al respecto representa, como se verá, Bélgica, donde se ha preferido resolver este tipo de conflictos a través del acuerdo y la negociación entre las partes. 


\title{
Palabras clave
}

Austria; Bélgica; cantones; coerción federal; federación; Italia; Länder; Portugal; regiones; Suiza.

\begin{abstract}
This work shows the instruments that different States of our legal environment have to remedy situations of serious breach by the Member States or regions of their constitutional duties that may endanger the respective Federation. All this, preceded by a synthetic exposition of the territorial context established by each one of the Constitutions of the studied countries, within which the mentioned instruments take on their true meaning. Specifically, the cases of Portugal, Italy, Austria, Switzerland and Belgium are shown, being able to observe the diversity of techniques, as well as the bodies involved in federal coercion, which find their explanation in the special characteristics of each order. A particular case in this respect represents, as will be seen, Belgium, where it has been preferred to resolve this type of conflict through agreement and negotiation between the parties.
\end{abstract}

\section{Keywords}

Austria; Belgium; cantons; federal coercion; federation; Italy; Länder; Portugal; regions; Switzerland. 


\section{SUMARIO}

I. INTRODUCCIÓN. II. PORTUGAL: 1. La configuración territorial portuguesa dentro de la singularidad de su Constitución. Evolución. 2. Disolución y cese de los órganos de autogobierno de las regiones. III. ITALIA: 1. La configuración territorial en la Constitución italiana. 2. Los poderes sustitutivos del Estado. La disolución de los Consejos Regionales y la remoción de los presidentes de las Juntas. IV. AUSTRIA: 1. El sistema federal austríaco. 2. El Senado austríaco y su papel en la coerción federal: la disolución extraordinaria de las Asambleas legislativas de los Länder. V. SUIZA: 1. El sistema federal suizo. 2. La garantía de la observancia del orden constitucional por parte de los cantones: 2.1. El control de la constitucionalidad del ordenamiento cantonal. 2.2. La inspección federal por parte del Gobierno. VI. BÉLGICA: 1. La complejidad del federalismo belga. 2. La resolución de los conflictos entre la Federación y las comunidades y regiones. VII. A MODO DE CONCLUSIÓN. Bibliografía.

\section{INTRODUCCIÓN}

Es habitual que las constituciones de los Estados compuestos prevean mecanismos de lo que ha dado en llamarse ejecución o coerción federal para aquellas situaciones de incumplimiento constitucional grave por parte de un estado miembro o región autónoma. Como se ha puesto de manifiesto, dichos mecanismos suponen en todos los casos dotar al Estado central o federación de instrumentos para combatir el incumplimiento de obligaciones por parte de las entidades descentralizadas, pero no a la inversa (Gómez Orfanel, 2005: 41-42), por lo que no constituyen solo un método de solucionar conflictos territoriales de cierta entidad, sino, también, un instrumento al servicio de la unidad del Estado o federación.

No obstante, los instrumentos de coerción pueden presentar distintos grados de intensidad, de acuerdo con las características propias de cada ordenamiento y el tipo de relación establecida - por motivos jurídicos o políticos- entre la federación y los respectivos estados federados o regiones que la conforman. $\mathrm{O}$, incluso, pueden ser sustituidos por mecanismos de acuerdo o colaboración tendentes a garantizar la unidad y estabilidad federativa, como ocurre en Bélgica. Con la excepción del caso italiano, la doctrina no les ha prestado demasiada atención, pues representan soluciones extremas a situaciones no deseables y que, en general y a diferencia de lo ocurrido en Espańa, no se han planteado en la práctica. Por todo ello, en el presente trabajo, antes 
de abordar cómo los países estudiados han diseñado este tipo de herramientas, nos detendremos en realizar una breve descripción del contexto constitucional y de la configuración territorial que la Constitución de cada uno de ellos lleva a cabo, pues pueden explicar, en cierta medida, el tipo de solución arbitrada en los respectivos ordenamientos.

\section{PORTUGAL}

\section{LA CONFIGURACIÓN TERRITORIAL PORTUGUESA DENTRO DE LA SINGULARIDAD DE SU CONSTITUCIÓN. EVOLUCIÓN}

La singularidad de la Constitución portuguesa ha sido puesta de manifiesto por la doctrina, desde el punto de vista formal, por la peculiaridad de su estructura y ordenación, y lo extenso de su texto y disposiciones, así como por lo detallado y pormenorizado del tratamiento de algunas materias. También se ha considerado singular por su contenido, al regular materias que no son objeto de tratamiento constitucional en otros textos, o no de forma tan detenida y extensa (así, por ejemplo, la reforma agraria, los sectores productivos, la planificación económica, y todo lo relacionado con la organización económica, en general). A esto habría que añadir, en el plano institucional, la constitucionalización expresa de instancias con difícil encaje en nuestro modelo constitucional, tales como el Movimiento de las Fuerzas Armadas o el Consejo de la Revolución ${ }^{1}$.

Asimismo, se ha destacado la peculiaridad de su origen, al no haber sido ratificada por el pueblo mediante referéndum (Noguera Fernández, 2013).

Todo ello llevó muy pronto a plantear la conveniencia de una amplia revisión de la Constitución, lo que andando el tiempo se ha traducido en siete reformas constitucionales entre los ańos 1982 y 2005.

1 Sobre esta peculiaridad y sus causas, véase Pérez Ayala (2007), quien señala como factores determinantes de esta la coyuntura político-militar de la Revolución de los Claveles y el protagonismo del Movimiento de las Fuerzas Armadas (MFA) en el proceso constituyente; la particularidad de la trayectoria histórica portuguesa y la ausencia de referentes constitucionales que pudieran servir para diseñar el nuevo marco constitucional en 1976; el influjo, además del constitucionalismo social europeo de la época, del constitucionalismo de las democracias populares de los países del Este, y, también, en alguna forma, del constitucionalismo de la descolonización.

Véase, también, Miranda (2007). 
Con carácter previo a la reforma de la cuestión territorial se habían llevado a cabo una serie de cambios que tuvieron por finalidad, entre otras cosas, abandonar la forma de gobierno semipresidencial en favor de una progresiva parlamentarización (principalmente, en la llevada a cabo en 1997)², o instaurar un Tribunal Constitucional al estilo de los existentes ya en otros países europeos (1982), sustituyendo una atípica forma de ejercer el control de constitucionalidad que, hasta la fecha y de acuerdo con el texto constitucional originario, le estaba encomendado al Consejo de la Revolución, depositario de la legitimidad revolucionaria del 25 de abril de 1976 y de carácter íntegramente militar, que contaba en la realización de sus tareas con la asistencia de un organismo de carácter jurídico dependiente de él, la Comisión Constitucional.

El turno para la organización territorial le llegó en la revisión de 1997, que incluyó importantes novedades respecto a las autonomías regionales cuyo régimen en el texto constitucional originario de 1976 era muy limitado, de carácter administrativo. Entre otras, se otorgó a las autonomías la potestad legislativa, lo que no fue valorado positivamente por algunos sectores de la doctrina, dada la quiebra de la unidad legislativa de la República que ello conllevaba ${ }^{3}$.

La renovada concepción de la autonomía regional que se inicia en 1997 se implementó en la reforma de 2004 con una ampliación de las competencias autonómicas, dejando de definirse en negativo para fijarse un haz de facultades pertenecientes a dicho ámbito.

No obstante, tampoco en aquella ocasión se adoptó una regionalización política integral, reservándose la autonomía política a las Azores y a Madeira y previendo meras regiones administrativas para el continente, lo que justifica la ausencia de una Cámara de representación territorial de nivel estatal y, con ello, la calificación de Portugal como un "Estado unitario regional», aun no estando esta calificación prevista en la Constitución (Miranda, 2007: 190).

Ese mismo ańo se introduce la posibilidad de que la transposición de los actos jurídicos de la UE al ordenamiento jurídico interno pueda realizarse no solo mediante ley o decreto ley estatal, sino también mediante normas legislativas regionales, los llamados decretos legislativos regionales (art. 112.8), participando de este modo las regiones en el proceso de construcción europea (Rodrígues Canotilho, 2010).

También se prevé la posibilidad de que la Asamblea legislativa de las regiones autónomas proponga al presidente de la República la convocatoria de

\footnotetext{
2 Sobre el sistema autonómico portugués tras la revisión de 1997 y antes de la de 2004, véanse Blanco de Morais (1999) y López Mira (2001).

3 Véase la nota anterior.
} 
un referéndum de ámbito regional de carácter vinculante "sobre cuestiones de relevante interés específico regional» (arts. 115.13 y 232.2), cuya decisión corresponde al jefe de Estado.

Se amplían, asimismo, las competencias legislativas de las regiones autónomas, eliminando la referencia al interés especifico regional como criterio justificativo de sus decretos legislativos, con el único límite de las materias reservadas a los órganos de soberanía (art. 228.1). Pero incluso este límite puede sortearse, ya que se admite la posibilidad de que las regiones legislen «en materias de reserva relativa de la Asamblea de la República, mediante autorización de esta» (art. 227.1.b), si bien con ciertas excepciones que a continuación se prevén en esta misma disposición. También se suprime la referencia a los principios fundamentales de las leyes generales de la República como marco en el que han de encuadrarse los decretos legislativos regionales que, de acuerdo con lo dispuesto en el art $227.1 \mathrm{c}$ ), pueden ya desenvolver para el ámbito regional los principios o bases generales de los regímenes jurídicos respectivos.

\section{DISOLUCIÓN Y CESE DE LOS ÓRGANOS DE AUTOGOBIERNO DE LAS REGIONES}

En este contexto de refuerzo de la autonomía territorial y su configuración como autonomía política, la intervención estatal en las regiones se relaja. Así, la figura del «ministro de la República» — representante del Estado en la región autónoma - es reconfigurada, pasando a tener la nueva denominación de "representante de la República», que, como advierte Pérez Ayala (2007: 120-121), apunta hacia una desgubernamentalización del cargo. Dicho representante es nombrado y separado del cargo por el presidente de la República, ahora "oído el Gobierno", en tanto que con anterioridad era propuesto por este. En cuanto a sus funciones, se suprimen las relativas a la supervisión de los servicios del Estado en la región.

Esa relajación afecta también a la coerción estatal sobre las autonomías, suprimiéndose la referencia existente hasta el año 2004 a la posibilidad de disolución de las Asambleas legislativas regionales por el presidente de la República "por iniciativa propia o a propuesta del Gobierno» (art. 133.j) en el supuesto de comisión de «actos contrarios a la Constitución» (art. 234.1)

4 Esta condición de la disolución fue en su día criticada por Soares Martinez (1978: 254), pues estimaba que también la Administración central realizaba constantemente actuaciones contrarias a la Constitución sin que ello sirviera de fundamento para la suspensión o la disolución de los órganos correspondientes. 
redirigiéndose ahora al procedimiento regulado en el art. 172 para la eventual disolución de la Asamblea de la República «con las debidas adaptaciones». De acuerdo con ello, la disolución sigue correspondiendo al presidente de la República previa audiencia - a falta de una Cámara de representación territorial- del Consejo de Estado (en cuya composición participan los propios presidentes de los Gobiernos regionales, además del jefe del Estado — que lo preside-, el presidente de la Asamblea, el primer ministro, el presidente del Tribunal Constitucional y el defensor del Pueblo) y de los partidos con representación en la Asamblea regional correspondiente (nueva redacción del art. 133.j y del art. 234.1).

De acuerdo con lo dispuesto en el apartado segundo del art. 234, la disolución de la Asamblea legislativa de la región autónoma supone la dimisión del Gobierno regional, que habrá de limitarse a los actos estrictamente necesarios para asegurar la administración de los asuntos públicos hasta la toma de posesión del nuevo Gobierno tras las elecciones, que han de tener lugar en el plazo de sesenta días de acuerdo con la legislación vigente en cada momento, so pena de invalidez del decreto de disolución (art. 113.6). Disuelta la Asamblea, los diputados y la Comisión permanente continúan en sus funciones hasta la primera reunión de la nueva Cámara después de la elección subsiguiente (art. 234.3).

\section{ITALIA}

\section{LA CONFIGURACIÓN TERRITORIAL EN LA CONSTITUCIÓN ITALIANA}

El título $\mathrm{V}$ de la Constitución italiana (en adelante, CI) contiene la regulación territorial de la República, esto es, la referida a las regiones, las provincias y los municipios, todos ellos entes autónomos con estatutos, funciones y poderes propios, de acuerdo con los principios fijados en la Constitución (art. $114 \mathrm{CI}$ ).

Dentro de las regiones, Friuli-Venecia Julia, Cerdeña, Sicilia, Trentino-Alto Adigio/Tirol del Sur y el Valle de Aosta gozan de «formas y condiciones particulares de autonomía», de acuerdo con sus respectivos estatutos especiales adoptados mediante ley constitucional. A su vez, la región de Trentino-Alto Adigio/Tirol del Sur está constituida por dos provincias autónomas, Trento y Bolzano.

No obstante, otras regiones, a iniciativa propia y tras oír a los entes locales, pueden beneficiarse de nuevas condiciones de autonomía en materia legislativa, judicial (juzgados de paz), educativa y medioambiental, a través de 
ley aprobada por las Cámaras por mayoría absoluta sobre la base de lo acordado entre el Estado y la región interesada (art. $116 \mathrm{CI}$ ).

El art. 117 CI fija los criterios de distribución de competencias entre el Estado y las regiones, determinando cuáles son las competencias legislativas exclusivas de aquel y las concurrentes entre ambos, así como una competencia residual de las regiones en todas aquellas materias no expresamente reservadas al Estado. En cuanto a la potestad reglamentaria, se atribuye al Estado en todas aquellas materias en las que les corresponde la legislación exclusiva, salvo que se haya delegado en las regiones, correspondiéndoles a estas, por lo demás, en relación con cualquier otra materia.

De otro lado, se permite a las regiones, en ámbitos materiales de su competencia, concluir acuerdos o tratados con otros entes territoriales o, incluso, Estados, siempre dentro de las formas y casos establecidos por una ley estatal.

Las regiones se encuentran representadas en el Senado, el cual, dejando al margen los elegidos en la circunscripción del extranjero (a la que corresponden seis escaños) y los senadores vitalicios, consta de 309 escaños, cuyo reparto entre aquellas se realiza proporcionalmente a su población, no pudiendo corresponder a ninguna región un número de senadores inferior a siete, en tanto que a Molise le corresponden dos y al Valle de Aosta, uno (art. 57 CI). La elección se verifica por sufragio universal y directo entre los electores del respectivo territorio (art. $58 \mathrm{CI}$ ), teniendo el cargo de senador, al igual que el de diputado, la duración de cinco años (art. 60 CI).

A la Cámara Alta le corresponden, con carácter general, las mismas funciones que a la Cámara de Diputados, no teniendo un protagonismo especial en el ejercicio de los mecanismos de coerción, a excepción de los senadores y diputados que formen parte de la Comisión mixta para las cuestiones regionales, en lo que se refiere a la posible disolución de las Asambleas regionales y a la remoción de los presidentes de las Juntas, como a continuación veremos.

\section{LOS PODERES SUSTITUTIVOS DEL ESTADO. LA DISOLUCIÓN DE LOS CONSEJOS REGIONALES Y LA REMOCIÓN DE LOS PRESIDENTES DE LAS JUNTAS}

El ordenamiento italiano establece distintos grados de intensidad de la intervención estatal en las regiones, dependiendo del peligro que la actuación de estas implique para los intereses generales del país, para los derechos de los ciudadanos o para la unidad jurídica o económica de la República, pudiendo llegar su presidente a decretar la disolución del Consejo Regional y la remoción del presidente de la Junta en los casos más graves. 
$\mathrm{El}$ art. 117. $5 \mathrm{CI}$ prevé la posibilidad de que las regiones y las provincias autónomas de Trento y Bolzano participen, en las materias de sus competencias, en las decisiones dirigidas a la formación de los actos normativos comunitarios, así como que procedan a la actuación y ejecución de los acuerdos internacionales y de los actos de la Unión Europea, de acuerdo con el procedimiento que se establezca en una ley estatal. Para el caso de que la actuación regional no se considere adecuada, se prevé un "poder sustitutivo» del Estado cuyas modalidades de ejercicio serán reguladas por una ley estatal.

En un sentido más amplio, el párrafo segundo del art. $120 \mathrm{CI}$ prevé otro supuesto de intervención estatal, cuya consagración constitucional tuvo lugar con la aprobación de la Ley constitucional de 18 de octubre de 2001, aunque con anterioridad el Estado ya había reivindicado dicho poder ${ }^{5}$. De acuerdo con lo establecido en el citado precepto, el Estado podrá adoptar medidas de ejecución no solo respecto a los órganos de las regiones, sino también de las ciudades metropolitanas, de las provincias y de los municipios en el caso de contravención de normas y tratados internacionales, de la normativa comunitaria, o, simplemente, de peligro grave para la salud y la seguridad pública. También podrá darse la sustitución cuando lo exija la unidad jurídica o económica, y, en particular, la tutela de los niveles esenciales de las prestaciones concernientes a los derechos civiles y sociales, prescindiendo de los límites territoriales de los Gobiernos locales. Como ha puesto de manifiesto Gómez Orfanel (2005: 52), se trata de una ejecución sustitutiva por razones de incumplimiento de deberes jurídicos, pero también por razones con un alto componente discrecional, que acercaría este artículo a la regulación española.

Los límites al Gobierno en su actuación vienen definidos también por la ley, que establecerá el procedimiento para garantizar que los poderes sustitutivos son ejercitados con respeto a los principios de subsidiariedad y colaboración leal. En la actualidad, esa es la ley n. 131/2003 (legge La Loggia), Disposizioni per l'adeguamento dell'ordinamento della Repubblica alla L.Cost.18 ottobre, 2001, n. 3.

La doctrina se ha planteado el alcance de los poderes de sustitución previstos en los arts. 117. 5 y 120.2 CI. A este respecto, si bien parece ampliamente compartida la opinión de que pueden tener tanto carácter reactivo como preventivo (Morana, 2018: 351), no resulta tan pacífica la cuestión relativa al tipo de poderes que pueden ejercerse. Así, Veronesi (2002), partiendo del contenido de dichos preceptos, concluye que la sustitución contemplada en el art. 120.2 se trataría de una actuación meramente administrativa, dado que se reconoce al Gobierno, sin distinguir entre regiones y otros entes que no tienen competencias legislativas, posición que, como veremos enseguida, no

Así lo pone de manifiesto Fontana (2018: 381). 
se ha visto confirmada en la práctica. Por el contrario, el art. 117.5, al referirse al incumplimiento de los deberes de desarrollo y ejecución de acuerdos internacionales y actos de la Unión Europea, podría albergar también sustituciones de tipo legislativo ${ }^{6}$, posibilidad que parece confirmar con carácter general la jurisprudencia constitucional, la práctica política y el desarrollo legislativo constituido por lo dispuesto en la Ley 131/20037.

En cualquier caso, afirma Fontana (2018: 382) que los poderes de sustitución del Estado se han visto ampliados progresivamente como consecuencia de las relaciones con el ordenamiento comunitario, dado que los incumplimientos regionales terminan por causar la responsabilidad estatal frente a la Unión Europea.

La Sentencia de la Corte Constituzionale 177/1988 sirvió de base y referencia para fijar los límites de la intervención estatal en estos casos. A ella se debe el haber integrado en el principio de legalidad la garantía del correcto ejercicio de los poderes sustitutivos. Como consecuencia de ello, la ley estatal debe disciplinar los presupuestos sustanciales y las condiciones procesales de la sustitución que ha de recaer en el Gobierno mismo y no en la Administración. Se trataría con ello, además, de compaginar los intereses esenciales y valores fundamentales que legitiman la intervención sustitutiva con la garantía de la de la autonomía política de los entes sustituidos y de sus competencias constitucionalmente reguladas.

Fue precisamente en este modelo en el que se inspiró la reforma constitucional de 2001, pese a lo cual los citados artículos se han considerado uno de los aspectos controvertidos y problemáticos de dicha reforma (Mainardis, 2007). Pues, aunque se entiende que se han de activar con la finalidad de tutelar la unidad e indivisibilidad de la República ex art. $5 \mathrm{CI}$ y garantizar ciertos derechos fundamentales indeterminados, son muchos los aspectos que quedan en la indefinición y, por tanto, en la incerteza, mitigada parcialmente por algunos pronunciamientos constitucionales, que han aclarado que el art. 120.2 CI no permite la activación de todos los posibles poderes sustitutivos, sino que se refiere solo a aquellos de naturaleza extraordinaria, necesarios para remediar «emergencias institucionales de particular gravedad» (así, las sentencias 43/2004 y 69/2004) ${ }^{8}$.

Muy recientemente, el Gobierno ha ejercitado por primera vez en la historia de Italia los poderes sustitutivos que le confiere el art. $120 \mathrm{CI}$, lo que ha producido un cierto debate político?. La situación que ha dado lugar a la intervención

\footnotetext{
Respecto a los poderes de sustitución, véanse también Mainardis, 2001 y 2007.

Se detiene en todos estos aspectos Fontana (2018: 384).

8 Se detienen en el contenido de dichas sentencias Buffoni (2007) y Fontana (2018: 384).

9 De las circunstancias del caso y del debate suscitado, se da cuenta en https://bit. ly/3kPPKsr y https://bit.ly/35ZdyUz.
} 
estatal ha sido la negativa de la región de Apulia a adaptar su normativa electoral a la Ley 20/2016 respecto al principio de igualdad entre hombres y mujeres en el acceso a los cargos electivos, pese a las advertencias previas del presidente del Consejo de Ministros, Giussepe Conte. Concluido el plazo otorgado por este a la región para que se adecuara a lo dispuesto en la normativa electoral italiana, el Gobierno dictó un decreto ley el 31 de julio del presente año ${ }^{10}$ introduciendo en la legislación electoral regional, «a fin de asegurar el pleno ejercicio de los derechos políticos y la unidad jurídica de la República», la denominada regla de «doble preferencia de género», de acuerdo con la cual cada elector puede emitir dos votos de su preferencia, de los cuales uno se reserva a un candidato de sexo distinto al otro ${ }^{11}$. En dicha norma se afirma que el incumplimiento por parte de la normativa regional de principios fundamentales fijados en la ley estatal integra el supuesto de hecho de incumplimiento normativo al que se refiere el art. 120 CI y, en consecuencia, constituye el presupuesto necesario para la asunción de las medidas sustitutivas que en él se contemplan. Para asegurar su eficacia, se nombra comisaria a la prefecta de Bari, a quien se encarga la adopción de las medidas necesarias para garantizar la igualdad de género en la configuración de las listas electorales de la región, así como la determinación de las disposiciones regionales incompatibles con la legislación nacional.

Habrá de esperarse para ver cuál será la reacción de la doctrina respecto al contenido y límites de la intervención practicada, así como en lo referido a la posibilidad de control por parte de la Corte Costituzionale, pues responde a un supuesto de hecho nunca afrontado por esta hasta el momento relativo a una decisión eminentemente política que, en general, queda en manos de los órganos regionales. A ello ha de añadirse que el control sustitutivo ha sido una cuestión reservada tradicionalmente a la jurisdicción contencioso-administrativa, aunque su propia calificación como acto controlable judicialmente es ya controvertida. De hecho, una parte de la doctrina sostiene que se trata de un acto político y, por tanto, infiscalizable ${ }^{12}$.

En los casos más graves de violaciones de la ley o de realización de actos contrarios a la Constitución por parte de las regiones, el art. 126 CI prevé que

10 El conocido como decreto ley Boccia-Bonetti, en alusión a los dos ministros de los que partió la propuesta de intervención.

11 Apulia era la única región incumplidora de entre las que habían de celebrar las elecciones el 20 y el 21 de septiembre del mismo año, ya que Liguria se había adecuado previamente.

12 Sobre las distintas posiciones adoptadas tradicionalmente por la doctrina al respecto pueden ilustrar Gori (2013), Pinelli (2013), Cameli (2005), De Leonardis (2009) y Sofia (2006). 
«el Presidente de la República acordará por decreto motivado la disolución del Consejo Regional y la remoción del Presidente de la Junta». Dados los términos imperativos utilizados en dicho artículo, parece que se trata de una intervención debida, teniendo que valorar únicamente el presidente de la República si se produce la situación requerida de intervención. No obstante, la doctrina ha convenido en afirmar que la contravención grave de la ley o la actuación contraria a la Constitución han de ser reiteradas y debe tratarse de una situación para la que el Estado no cuente con medios ordinarios de resolución, como puede ser el recurso de inconstitucionalidad vía art. $127 \mathrm{CI}$ o el conflicto vía art. 134 CI (Barbera y Fusaro, 2016), pues se trata de una disolución de carácter «sancionador» ${ }^{13}$.

Por su parte, en el segundo inciso de ese mismo artículo se prevé que «podrán, asimismo, ser acordadas la disolución y la remoción por razones de seguridad nacional», de donde parece deducirse que, en este caso, el presidente de la República no solo habrá de valorar que se da el supuesto de hecho habilitante, sino también la oportunidad del instrumento allí previsto para atajar el problema de seguridad nacional que se plantee. A este respecto, la doctrina ha subrayado que el precepto ha de funcionar como una verdadera "cláusula de cierre» o último recurso (Barbera y Fusaro, 2016). De acuerdo con lo señalado por la Corte Costituzionale en la Sentencia 196/2003, corresponde a la región afectada la regulación de los modos y formas de la prorrogatio del cargo de los miembros de la Asamblea respectiva, si bien ha advertido de que, en pura lógica, no cabe prórroga alguna si la permanencia en el cargo supone un peligro para la seguridad nacional. Asimismo, la Corte ha aclarado que los poderes de los órganos prorrogados han de limitarse a la administración ordinaria, habiendo llegado a anular leyes dictadas por una Asamblea en régimen de prorrogatio (Sentencia 68/2010). Por su parte, la determinación de las consecuencias en orden al ejercicio de las funciones hasta la elección de los nuevos órganos corresponde a la ley estatal ${ }^{14}$.

En ambos casos, el decreto presidencial se dictará previa audiencia a la Comisión de diputados y senadores para las cuestiones regionales, cuyo parecer no vinculante podrá servir, no obstante, para evaluar correctamente la gravedad de la situación que se presenta, así como para aportar alternativas o proponer condiciones o modificaciones a la intervención estatal, de acuerdo con lo que establezca una ley de la República (Sterpa, 2018: 409-410).

13 La expresión scioglimento sanzionatorio es de Mancini (2016), y es acogida también por otros autores como Sterpa (2018: 407).

14 Sobre las distintas implicaciones de esta intervención estatal, véase Fontana (2004: 407-408). 


\section{AUSTRIA}

\section{EL SISTEMA FEDERAL AUSTRÍACO}

La condición de Austria como Estado federal se recoge explícitamente en el art. 2 de su Constitución (en adelante, B-VG), señalando que «se compone de los Estados (Länder) autónomos de Burgerland (Burgerlland), Carintia (Kärnten), Baja Austria (Niederösterreich), Alta Austria (Oberösterreich), Salzburgo (Salzburg), Estiria (Steiermark), Tirol, Vorarlberg y Viena (Wien)». Los nueve Länder tienen el mismo nivel de autonomía constitucional, que incluye la potestad legislativa. La única peculiaridad se halla en Viena, la capital, por ser al mismo tiempo un Land y un municipio.

Según lo establecido por el Tribunal Constitucional austríaco, el principio federal se basa sobre tres elementos sustantivos: la distribución de las competencias legislativas y administrativas; la participación de los Länder en la legislación y en la Administración federal (lo que se llama «Administración federal indirecta», ejecutada principalmente por el gobernador de cada Land), y la autonomía constitucional de los Länder (Gamper, 2004: 16).

Desde el punto de vista político, el sistema federal implantado en la Constitución austríaca de 1920 fue el resultado de una fórmula de compromiso entre los socialdemócratas, que eran partidarios de un Estado fuertemente centralizado, y el partido social cristiano, que prefería un sistema similar a Suiza (Bussjäger, 2010: 12) ${ }^{15}$.

Desde el punto de vista técnico-jurídico, la Constitución Federal austríaca fue diseñada fundamentalmente por Hans Kelsen, bajo el espíritu del positivismo normativo. En ella se acuña una federación con fuertes componentes unitarios y una clara preponderancia del nivel federal de gobierno respecto del poder de los Länder. Se trata, en realidad, de un país cuya Administración se encuentra muy centralizada y que se resiste tradicionalmente a dotar de más competencias a los Länder, lo que ha llevado a la doctrina a afirmar que es una "Federación sin federalismo» (Erk, 2004). De hecho, los distintos intentos de reforma del sistema federal pueden considerarse fallidos ${ }^{16}$. Los austríacos quieren, al mismo tiempo, unas entidades regionales fuertes y un sistema legal uniforme, lo cual es, simplemente, incompatible (Gamper, 2004: 17).

Por ello, las distintas modificaciones que desde su aprobación ha sufrido la norma fundamental han aumentado progresivamente los poderes de la

15 Sobre la formación del federalismo austríaco y sus contornos actuales, véase también Bussjäger, 2017.

16 Sobre los distintos intentos de reforma llevados a cabo, véase Bussjäger (2010: 11-39). 
Federación, que desempeña, además, un papel coordinador, en materia tanto legislativa como administrativa (Bussjäger, 2010: 12).

En cualquier caso, el federalismo es uno de los principios constitucionales básicos en Austria, cuya modificación, de acuerdo con la interpretación que la doctrina y la jurisprudencia han dado al art. $44.3 \mathrm{~B}-\mathrm{VG}$, requiere su aprobación por el pueblo en referéndum y por las dos terceras partes del Parlamento $^{17}$. Por su parte, las modificaciones de la Constitución que supongan una reducción de las competencias de los Länder necesitan el consentimiento del Consejo Federal.

\section{EL SENADO AUSTRÍACO Y SU PAPEL EN LA COERCIÓN FEDERAL: LA DISOLUCIÓN EXTRAORDINARIA DE LAS ASAMBLEAS LEGISLATIVAS DE LOS LÄNDER}

La representación de los Länder en el nivel federal tiene lugar a través del Senado o Bundesrat, que ejerce un papel dentro del sistema en concordancia con el federalismo débil austríaco.

El Bundesrat es orgánica y funcionalmente la segunda Cámara del Parlamento Federal, que ostenta la representación de los Länder. Por ello se suele hacer referencia a él también como Cámara o representación de los Estados (Länderkammer o Ländervertretung) ${ }^{18}$. Así, los miembros de la Asamblea Federal son elegidos por los Parlamentos de los Länder proporcionalmente a su población (art. $34 \mathrm{~B}-\mathrm{VG}$ ), que de esta manera ve representados sus intereses en el Poder Legislativo federal. Por tanto, el mandato de los Bundesräter coincide temporalmente con la legislatura de la Dieta que los elige. Los escaños correspondientes a cada $L$ and se distribuyen de modo proporcional entre los partidos presentes en el respectivo Landtag o Parlamento estatal (art. 35 B-VG), de manera que al segundo partido le corresponda, al menos, un puesto. Los elegidos pueden ser o no miembros de la respectiva Cámara regional, pero en ningún caso pueden formar parte simultáneamente de la Cámara Baja o Nationalrat, pues ambos cargos son incompatibles (art. $59 \mathrm{~B}-\mathrm{VG}$ ).

17 En realidad, el art. 44.3 B-VG prevé tales exigencias para la revisión total de la Constitución, pero tanto la doctrina como la jurisprudencia han asimilado a la revisión total la modificación de sus principios básicos. A este respecto, véase Bussjäger (2010: 12).

18 Como pone de manifiesto Vernet i Llobet (1996: 130 y ss.), la actual denominación de Bundesrat se debe a la Constitución de 1929, que lo concibió como una Cámara de representación de los estados federados y de las corporaciones, aunque esta última representación nunca llegó a ponerse en práctica. 
No obstante, el Consejo Federal es definido por la doctrina y por la opinión pública, en general, como una Cámara de representación devaluada que, en realidad, refleja la propia endeblez del federalismo austriaco. Durante largo tiempo los Länder no han defendido sus intereses a través de la Cámara Alta (que, de facto, no los representa), buscando otras alternativas de negociación y colaboración vertical y horizontal ${ }^{19}$.

Desde esa perspectiva, no desempeña un papel relevante en la política interna del país, así como tampoco desde el punto de vista del control del Gobierno, pues no tiene mecanismos suficientes para llevarlo a cabo y tampoco utiliza aquellos de los que dispone. Lo mismo sucede respecto a la función legislativa, donde aparece como una Cámara débil que no sirve para representar los intereses regionales.

En definitiva, el Senado austriaco se presenta como una Cámara con pocas funciones propias y cuyo peso político resulta muy mermado por la propia dinámica de los partidos en dicho país y por la preponderancia del Nationalrat como Cámara de nivel federal, razones a las que, en parte, se debe que la estrategia territorial de los Länder no incluya la utilización cotidiana del Bundesrat (Vernet i Llobet, 1996: 138).

Una excepción a lo dicho la encontramos, precisamente, en materia de coerción estatal, donde la decisión sobre el apoyo o no al presidente federal le corresponde en exclusiva, lo que cuantitativamente no resulta muy relevante, por lo excepcional del ejercicio de dicha función, pero, llegado el caso, sí pudiera serlo desde el punto de vista cualitativo, como se ha demostrado en el caso de español.

Efectivamente, de acuerdo con lo establecido en el art. 100 B-VG, el Senado o Bundesrat ha de dar su autorización para que el presidente federal pueda proceder a acordar de forma extraordinaria la disolución de un Land a iniciativa del Gobierno Federal, pudiendo acordarse una sola vez por el mismo motivo. Esta limitación se ha visto por Gómez Orfanel (2005: 54) como una invitación a la imaginación lingüística para superar tal obstáculo. La Constitución no aclara qué causas pueden dar lugar a tal decisión, por lo que será el Gobierno el que tenga que valorar las circunstancias concurrentes en cada caso.

El acuerdo de la Cámara Alta, para ser válido, ha de tomarse estando presentes la mitad de sus miembros, debiéndose alcanzar la mayoría de dos tercios, sin que los delegados del Landtag respecto del que se discute la disolución puedan participar en la votación (art. 100.1 B-VG).

19 De entre ellas, la más destacada es la llamada Conferencia de Gobernadores de los Länder. Al respecto, véase Bussjäger, 2017: 184 y ss. 
De concederse la autorización, el presidente federal dictará el decreto correspondiente, acompañado por la convocatoria de elecciones en el plazo de tres semanas, convocándose el nuevo Landtag dentro de las cuatro semanas siguientes a las elecciones (art. 100.2 B-VG). Ello no impide, como se ha hecho notar por la doctrina ${ }^{20}$, que el nuevo Parlamento pudiera actuar de forma semejante al anterior, lo que, unido a la imposibilidad de disolver nuevamente por la misma causa, llevaría a poner en cuestión la eficacia real del procedimiento.

\section{SUIZA}

\section{EL SISTEMA FEDERAL SUIZO21}

Suiza es hoy una Federación compuesta por veintitrés cantones (el último, Jura, que se separó de Berna tras un largo proceso que concluyó en 1978), de los cuales, tres se encuentran divididos en dos semicantones. Se trata de un típico federalismo por agregación, en cuanto que surge del pacto — de origen fundamentalmente defensivo- entre los tres cantones originarios (Schwyz, Uri y Unterwalden) en torno al año 1291, a partir del cual la Confederación se fue formando poco a poco ${ }^{22}$.

Los cantones se ven representados a nivel federal en el Senado o Ständerat, que constituye el elemento federalista. Dicho órgano se sitúa en una posición de completa igualdad respecto al Congreso o Nationalrat, pues se trata de mantener un equilibrio entre las dos soberanías, la democrática y la cantonal ${ }^{23}$. También, como veremos, las funciones en relación con el ejercicio de la coerción confederal corresponden a ambas Cámaras y no, como ocurre en otros ordenamientos —incluido el nuestro-, únicamente a la Cámara de representación territorial.

Como en otro lugar ya pusimos de manifiesto, Suiza se sostiene sobre la idea de la igualdad no solo de los individuos, sino también de los cantones, al tiempo que se garantiza y se promociona la diversidad, que es uno de los principales valores constitucionales (Rodríguez-Patrón, 2014).

20 Así, Gómez Orfanel (2005: 54), citando a Vernet i Llobet (1996), plantea la posibilidad de que se entrara en una perniciosa sucesión de disoluciones y elecciones.

21 Un estudio más detenido del sistema federal suizo puede consultarse en Rodríguez-Patrón (2014).

22 Sobre la evolución histórica del federalismo suizo, véase Lang y Sanna, 2005: 107 y ss.

23 Acerca del Senado suizo, véase Rodríguez-Patrón (2008). 
En la reforma total que tuvo lugar en 1874 y las sucesivas enmiendas posteriores (aproximadamente, 150) que culminan en la Constitución de 1999, las estructuras del Estado se fueron progresivamente reforzando, al tiempo que sus atribuciones se vieron considerablemente ampliadas.

Debido a la interdependencia política entre los cantones y la Confederación, en la práctica quedan muy pocos espacios en los cuales pueda decirse que los cantones son absolutamente autónomos. Este fenómeno se vio acentuado a partir de la aprobación de la Constitución de 1999, en la que el elemento de la cooperación, encarnado, entre otros, en el principio del poder compartido, fue ganando importancia frente a la autonomía cantonal. Debido precisamente a este último principio y la creciente interdependencia de las distintas tareas públicas, no siempre resulta sencillo realizar una clara distinción entre asuntos federales y cantonales.

Desde el punto de vista funcional, el reparto de competencias entre la Federación y los cantones es particularmente complejo, pese a que el art. 3 de la Constitución (en adelante, CFS) dé la impresión de que existe una división lineal entre competencias enumeradas (correspondientes a la Federación) y competencias residuales (pertenecientes a los cantones), pues las previsiones son distintas según la materia de que se trate. No obstante, si se observa el texto de la Constitución pueden individualizarse competencias exclusivas de nivel federal, cantonales (sometidas siempre al principio de prevalencia del derecho federal, de acuerdo con los establecido en el art. 49.1 CFS), concurrentes y paralelas (en cuyo ejercicio tanto los cantones como la Federación deben tender a la compatibilidad) (Lang y Sanna, 2004: 112).

Lo que sí parece claro es que el federalismo suizo está llamado a articularse, no sobre subdivisiones rígidas, sino sobre convenciones y acuerdos entre todas las partes, de acuerdo con la fórmula del federalismo cooperativo, pero bajo la suprema autoridad de la Confederación.

El principio de subsidiariedad determina la distribución territorial de competencias, así como el modo de ejercerlas. En este sentido, el apartado segundo del art. 46 CFS obliga a la Federación a otorgar a los cantones «el margen de acción más amplio posible» y a tener en cuenta «las particularidades cantonales», debiendo velar (wahrt, en la versión alemana; respecte, en la francesa) por la autonomía de los cantones, «en el marco de la Constitución federal» (art. $47 \mathrm{CFS})^{24}$.

Sin embargo, el hecho de que el apartado 2 del art. 46 CFS establezca que la Federación «asumirá las funciones que requieran ser reguladas de forma

24 Pese a que el art. 3 CFS establezca que «los cantones son soberanos». Porque en ese mismo artículo se recuerda que lo son «en el marco de la Constitución federal». Véase, en este sentido, Forster (2000: 132). 
uniforme» ha sido interpretado como una forma de adjudicar la «competencia de las competencias» a la Federación, ya que es a ella a la que le corresponde determinar — sin que esté previsto control alguno (art. 189 CFS) — cuándo se requiere ese tipo de tratamiento $\mathrm{y}$, por tanto, qué competencias son de titularidad de la Federación (y no de los cantones). Dicho de otra forma, que el respeto al principio de subsidiariedad va a depender de la buena voluntad de la Federación (o, podríamos decir, haciendo un parangón con la jurisdicción constitucional, de su self-restraint). Dada la ausencia de una instancia judicial competente para declarar la inconstitucionalidad de las leyes federales (art. 190 CFS), se recurre, frecuentemente, al control mutuo de las fuerzas políticas (Thalmann, 2000: 166-167).

Una previsión acogida muy positivamente por la doctrina fue la cláusula contenida en el art. 49.1 CFS, según la cual «el Derecho Federal prima siempre sobre el Derecho Cantonal que le sea contrario», para los supuestos de colisión normativa (que no tienen por qué coincidir con una colisión competencial). La primacía del derecho federal es, por tanto, inequívoca. Así se vuelve a poner de manifiesto en el apartado segundo de ese mismo artículo, al encomendar a la Confederación la tarea de velar por que «los cantones respeten el Derecho federal». Como veremos enseguida, este deber de inspección abarca tanto el ámbito legal como el reglamentario, y, de forma más amplia, el administrativo (Forster, 2000: 135).

El principio de solidaridad cumple un importante papel también como bisagra del sistema de distribución competencial. El federalismo suizo encuentra un equilibrio adicional sobre la base de una compleja red de cooperación informal de agentes políticos, económicos, sociales e institucionales, que contribuyen a la unidad del país. En lo que se refiere a la Federación y a los cantones, la obligación de asistencia mutua se consagra en el art. 44 de la Constitución (principio de lealtad confederal) ${ }^{25}$. Esa obligación va más allá de un deber genérico de solidaridad, no pudiéndose enfocar desde un punto de vista jerárquico, sino de paridad.

\section{LA GARANTÍA DE LA OBSERVANCIA DEL ORDEN CONSTITUCIONAL POR PARTE DE LOS CANTONES}

\subsection{El control de la constitucionalidad del ordenamiento cantonal}

En el sistema suizo, en sintonía con sus peculiares características ya resumidas, el control de constitucionalidad de las leyes cantonales no tiene solo

25 Acerca del principio de lealtad confederal, véase Le Roy y Schoenenberger (2015: 69-70). 
un carácter judicial, sino que se encomienda a una pluralidad de órganos, entre los que se encuentran las jurisdicciones cantonales, la Asamblea y el Consejo Federal, y los propios Gobiernos cantonales.

Para asegurar el respeto al derecho federal, la Confederación puede adoptar tanto medidas preventivas como represivas. Dentro de las primeras se sitúa la aprobación federal de las constituciones cantonales o de los tratados cantonales por parte del Parlamento, en este último caso, cuando el Consejo Federal o algún cantón presente alguna objeción frente al tratado. Por lo demás, el derecho cantonal solo estará sometido a control preventivo cuando así lo prevea explícitamente una ley federal.

Por su parte, el control represivo puede consistir en la revocación de una norma cantonal, lo cual puede resultar problemático cuando tal norma ha entrado ya en vigor. Aunque el derecho federal prevé un control de largo alcance, normalmente estas medidas se limitan a un control de legalidad ${ }^{26}$.

En cuanto a la intervención judicial en los conflictos territoriales, esta se ve limitada por el hecho de que el Tribunal Supremo no tiene competencia para declarar nulas las leyes federales ${ }^{27}$, que se encuentran sometidas permanentemente, en cambio, a la posibilidad de ser anuladas mediante referéndum. Sí puede anular las leyes cantonales, cuando estas se oponen al derecho federal, pero no es frecuente que haga uso de esta competencia.

En cualquier caso, corresponde al Tribunal Federal conocer en única instancia de los litigios que se planteen en materia de derecho público (constitucional o administrativo) entre cantones o entre estos y la Confederación.

\subsection{La inspección federal por parte del Gobierno}

En un sentido más amplio, corresponde a la Confederación, de acuerdo con lo dispuesto en el art. 49.2 CFS, inspeccionar que los cantones cumplen el derecho federal. La inspección federal no es una competencia, sino un deber, y se despliega tanto sobre las facultades delegadas por la federación a los cantones como sobre las que se ejercen dentro de ámbito de autonomía propio de estos, incluyendo, en cualquier caso, las competencias legislativas y ejecutivas (art. 186.4 CE) ${ }^{28}$.

26 A este respecto, véase Rodríguez-Patrón, 2014: 350.

27 Sobre la evolución experimentada en el control de la constitucionalidad de las leyes federales, véase Gerpe y Barceló (2006: 127 y ss.) y Gambino (2007: 316-317).

28 Sobre la inspección federal, véanse Häfelin y Haller (2008: 352 y ss.) y Rodríguez-Patrón (2014: 349 y ss.). 
Dicho deber obliga principalmente al Gobierno, o Consejo Federal, que debe velar por la observación y la ejecución de las leyes y decisiones de la Asamblea Federal, así como por las de las sentencias de las autoridades judiciales federales (art. 182.2 CFS). Por ello, aunque conforme a lo dispuesto en el art. 178.1 CFS solo le corresponde dirigir su propia Administración, en la medida en que las Administraciones cantonales aplican el derecho federal, permanecen también bajo su inspección.

Las facultades que incluye la inspección son de diversa índole. Entre ellas, se encuentran la de dictar directivas aplicables a todos los cantones, la exigencia de informes periódicos y de autorización para determinados actos o la posibilidad de anular los actos cantonales contrarios a la legislación federal. Un caso peculiar constituye la ya citada firma de tratados entre cantones o de estos con algún país extranjero, que no requiere la autorización gubernamental, pero el Consejo Federal ha de ser informado de su celebración, pudiendo denunciarlos ante la Asamblea Federal si lo estima conveniente (art. 186.3 CFS). Asimismo, el Gobierno ha de velar por la observación de lo pactado (art. 186.4 CFS).

Cabe igualmente que la Federación suprima los subsidios a un cantón si incumple con sus obligaciones, debiendo siempre haber una relación entre la obligación incumplida y el subsidio que se suprime. Ese incumplimiento puede dar lugar también a la ejecución federal sustitutiva, pero debe acudirse a ella como ultima ratio. Por último, la Federación puede usar la fuerza militar para obligar a los cantones a cumplir con sus obligaciones, aunque en la práctica nunca ha recurrido a ella.

\section{BÉLGICA}

\section{LA COMPLEJIDAD DEL FEDERALISMO BELGA}

Como se ha puesto de manifiesto frecuentemente, el federalismo belga es particularmente complejo ${ }^{29}$. Al igual que Austria, Bélgica se constituyó como un Estado unitario, pero desde su fundación surgieron problemas como consecuencia de las diferencias lingüísticas entre los flamencos y los valones. Entre 1970 y 2003, la Constitución ha sido reformada cinco veces con el fin de consolidar un modelo federal cuyo nacimiento tuvo lugar en 1993 con una configuración sui generis determinada por una larga serie de compromisos

29 Véase, por todos, Cardoen (2011: 223). Sobre el origen y evolución del federalismo belga hasta el año 2009, véase De Cueto Nogueras (2009). 
entre posiciones contradictorias sobre la organización territorial del Estado. Como se ha puesto de manifiesto, estos compromisos tuvieron el objetivo de reducir los conflictos de la comunidad, y no de establecer una hoja de ruta bien diseñada para crear un Estado federal ejemplar ${ }^{30}$.

En cualquier caso, las reformas no han conseguido dar satisfacción a los intereses enfrentados, por lo que desde hace tiempo se proyecta una nueva modificación que busca acercar el país al modelo confederal ${ }^{31}$.

La federación belga se distribuye en comunidades lingüísticas y en regiones. Las comunidades, en consonancia con las tres lenguas oficiales, son las siguientes:

— La Comunidad neerlandófona («flamenca»), a la que pertenecen del territorio de Flandes y los habitantes de habla holandesa en Bruselas.

- La Comunidad francófona ("valona»), que engloba al territorio de Valonia y a los habitantes francófonos de Bruselas.

- Y la Comunidad germanoparlante, en la que se inscriben los nueve municipios de lengua alemana en territorio valón.

Por su parte, de acuerdo con criterios territoriales, existen tres regiones, que fueron creadas con las reformas del Estado de 1980 (Flandes y Valonia) y de 1988 (Bruselas), cuyos poderes se restringen al respectivo ámbito territorial, dentro del cual actúan con autonomía. Dichas regiones son Flandes, Valonia y Bruselas-Capital.

La Constitución belga (en adelante, CB) dedica el capítulo IV del título III a la autonomía territorial. En principio, el poder legislativo de las comunidades lo ostentan los respectivos Consejos comunitarios, elegidos mediante elecciones libres y directas. El poder ejecutivo, por su parte, recae en los Gobiernos regionales y comunitarios. Sin embargo, la Comunidad y la Región flamencas reunificaron sus instituciones legislativas y ejecutivas, de manera que Flandes tiene un único Parlamento y un único Gobierno. Los francófonos, en cambio, decidieron mantener separadas sus autoridades para la toma de decisiones. Así, la Región Valona y la Comunidad francófona (Valonia y la parte francófona de Bruselas) tienen, cada una, su rama legislativa y su rama ejecutiva propias. La organización de la Región de Bruselas es, por último, la más compleja. El Consejo de Bruselas y el Gobierno regional de Bruselas son los responsables de los asuntos regionales o de zona restringida, mientras que

30 Acerca de la consolidación de Bélgica como Estado federal, véase De Winter (2005).

31 Sobre las sucesivas reformas constitucionales en Bélgica y la reforma proyectada a la que se hace referencia en el texto, v. Mastromarino (2015). 
las comunidades flamenca y francófona son las autoridades competentes para abordar aquellos asuntos propios de dichas comunidades en Bruselas. La Comisión de las Comunidades de Bruselas se ocupa de abordar aquellos temas que atañen a ambas comunidades.

La naturaleza disgregante de este federalismo, debida, fundamentalmente, a las diferencias lingüísticas, se convierte, así, en la clave de bóveda de este sistema tomado en su conjunto, garantizando la participación de las comunidades lingüísticas en el proceso de decisión (Mastromarino, 2015: 66).

En cuanto a la Federación, esta solo tiene competencias en los asuntos que le hayan sido atribuidos formalmente por la Constitución y las leyes de desarrollo, como es el caso de las bases del derecho civil, mercantil y penal.

Las diferentes comunidades lingüísticas tienen también su reflejo en el Parlamento. Así, tanto los miembros de la Cámara de representantes como los del Senado se encuentran repartidos en grupos lingüísticos, francés y neerlandés, y, en el caso de la Cámara Alta, hay, además, un senador elegido por el Parlamento de la comunidad germana (art. $43 \mathrm{CB}$ ).

En concreto, el Senado está compuesto por sesenta senadores (con anterioridad a la sexta reforma del Estado contaba con 71), de los cuales, 29 son designados por el Parlamento flamenco, en su seno o en el del grupo neerlandés del Parlamento de la Región Bruselas-Capital, uno de los cuales al menos ha de estar domiciliado el día de su elección en dicha región; diez senadores designados por el Parlamento de la Comunidad francesa; ocho designados por el Parlamento de la Región de Valonia; diez designados por el grupo lingüístico francés del Parlamento de la Región de Bruselas-Capital, y un senador designado por el Parlamento de la Comunidad germanoparlante. La Cámara Alta cuenta, asimismo, con diez senadores cooptados, de los cuales seis serán nombrados por los flamencos y otros cuatro por los francófonos sobre la base de los resultados de las elecciones de la Cámara de Representantes.

La reforma de 2014 trajo consigo cambios relevantes en las funciones y competencias del Senado ${ }^{32}$. En primer lugar, deja de ser un órgano permanente, debido también al doble mandato de los senadores-diputados de los Parlamentos subnacionales, previéndose un mínimo de ocho convocatorias por ańo.

También a partir de ese momento se intensifica su función de asesoramiento, que lo convierte de alguna forma en un órgano consultivo, que carece de funciones de control del Gobierno, y con una debilitada participación en el proceso legislativo, pues con carácter general es a la Cámara de representantes a la que le corresponde, junto con el rey, la potestad legislativa, incluyendo la

32 Respecto a la composición y funciones de esta Cámara con anterioridad a la reforma, véase Scholsem (1995: 66 y ss.). 
iniciativa (arts. 74 y 75 CB). El bicameralismo perfecto solo tiene lugar en los casos establecidos en el art. $77 \mathrm{CB}$, por remisión del art. 75, únicos en los que el Senado puede ejercer la iniciativa, a saber: la revisión de la Constitución, las materias que exigen acuerdo de las dos Cámaras en virtud de lo dispuesto en la carta magna, las leyes de modificación de los límites de las regiones lingüísticas, que requieren para su aprobación una mayoría especial, de acuerdo con lo dispuesto en el art. $4 \mathrm{CB}^{33}$; las leyes referidas a las instituciones de la Comunidad germana y su financiación, y las leyes sobre financiación de los partidos políticos y control de los gastos electorales, así como las que se refieren a la organización del Senado y al estatuto de los senadores.

En todos aquellos casos en que es la Cámara de representantes la que ejerce la iniciativa, el texto aprobado por esta se envía al Senado, que puede aceptarlo como tal, en cuyo caso, se envía al rey por aquella para su sanción o enmendarlo. En este último caso, se envía nuevamente a la Cámara de representantes, que decide definitivamente si el texto se aprueba incorporando o no la enmienda propuesta por el Senado (art. 78 CB).

Por ley aprobada por la mayoría especial prevista en el art. $4 \mathrm{CB}$ pueden fijarse otras materias en las que ambas Cámaras deban participar en la aprobación de las leyes en pie de igualdad. La resolución de los posibles conflictos de competencia entre las dos Cámaras se encomienda a una comisión parlamentaria compuesta de manera paritaria por miembros de ambas de conformidad con lo establecido en una ley, que ha de adoptar sus decisiones por mayoría de las dos partes y, en caso de no obtenerse esta, por mayoría de dos tercios del total de sus miembros (art. $82 \mathrm{CB}$ ).

Para aprobar un proyecto de ley en el Senado se necesita ahora el voto favorable de 31 senadores, más la tercera parte de los miembros de cada grupo lingüístico, en tanto que antes de la reforma solo se requería el apoyo de quince senadores de los 61 que formaban parte del Senado. Por eso y por la general restricción de los poderes legislativos que ha sufrido el Senado, se ha hablado de la mise au frigo d'une institution (ibid:: 81).

Por todo ello, se ha subrayado la tendencia al unicameralismo marcada por la reforma, lo que, unido a que la transformación del Senado en una Cámara de elección indirecta, desposeída de la mayoría de los poderes legislativos, se ha interpretado como un paso más hacia le démantèlement du pays,

33 Este artículo determina la mayoría por la que han de aprobarse las leyes de modificación de los límites territoriales de las regiones: «[...] mayoría de los votos en cada grupo lingüístico de cada una de las Cámaras, con la condición de que esté presente la mayoría de los miembros de cada grupo y siempre que el total de los votos positivos emitidos en los dos grupos lingüísticos llegue a dos tercios de los votos emitidos». 
favoreciendo el camino de Bélgica hacia una disgregación creciente que la llevará a convertirse, según dicha opinión —y según los deseos de los nacionalistas flamencos-, en una confederación peculiar, lejos de los modelos históricos de Suiza, Estados Unidos o Alemania, pero capaz de conceder el máximo protagonismo político-institucional a las entidades subestatales, dejando al Estado central solamente un espacio de soberanía externa.

No obstante todo lo dicho, se ha advertido que no es posible definir al Senado belga solamente a partir de las categorías clásicas del bicameralismo, dado su carácter sui generis, que ha representado para el derecho comparado una experiencia única donde lo relevante no es ni el factor territorial ni el ideológico, sino la afiliación comunitaria (ibid.: 82).

\section{LA RESOLUCIÓN DE LOS CONFLICTOS ENTRE LA FEDERACIÓN Y LAS COMUNIDADES Y REGIONES}

El señalado carácter disgregante del federalismo belga, que ha mostrado a lo largo del tiempo una clara preferencia hacia el compromiso como práctica política de resolución de las controversias institucionales, ha llevado a un alto nivel de interdependencia entre los sujetos institucionales como posibilidad de superar el enfrentamiento lingüístico, introduciendo en el debate político nuevas fórmulas de diálogo multilateral (ibid:: 78).

Todo ello podría justificar el hecho de que el Estado no cuente con los poderes de coerción existentes en otros países con descentralización política del poder y que exista, en cambio, una tendencia a resolver los conflictos territoriales también por la vía del acuerdo. En este ámbito, se concede excepcionalmente un cierto protagonismo al Senado, al igual que en otros países del entorno ya citados.

La Constitución dedica su art. 143 a la prevención y solución de los conflictos de intereses entre los distintos niveles gubernamentales. En primer lugar y de forma preventiva, se recuerda a las comunidades, a las regiones y a la Comisión Conjunta de Comunidades que deben actuar con lealtad federal, tratando de evitar estos conflictos.

De acuerdo con lo dispuesto en el apartado 2 de dicho artículo, corresponde a la Cámara Alta pronunciarse, mediante dictamen motivado, acerca de los conflictos de intereses que puedan surgir entre las Asambleas que legislen mediante ley, ley federativa o disposiciones de las previstas en el art. $134^{34}$, en las condiciones y conforme a las modalidades que determine

34 Se trata de las leyes dictadas en virtud de delegación por parte de una ley federal. 
una ley aprobada por la mayoría prevista en el último párrafo del art. 4. Esa misma ley organizará el procedimiento tendente a prevenir y a resolver los conflictos de intereses entre el Gobierno Federal, los Gobiernos de la comunidad y de la región y el Colegio reunido de la Comisión Conjunta de Comunidades (art. 143.3 CB).

La citada ley en la actualidad es la Ley de 8 de agosto de 1980, sobre reformas institucionales, que diseńó el modo de abordar los conflictos, cuando estos ya se han producido, encomendando su resolución no al Gobierno federal sino al Senado o a ambas Cámaras mediante una ley adoptada por la mayoría especial descrita en el art. 4 CB.

\section{A MODO DE CONCLUSIÓN}

Los modelos estudiados muestran una variedad de instrumentos destinados a reconducir situaciones en las que, debido a la actuación de algún ente territorial, se ponen en peligro el ordenamiento constitucional y la unidad del Estado. Tales herramientas resultan, por lo general, coherentes con las características de la distribución territorial presente en cada ordenamiento y el tipo de relaciones que mantienen los entes territoriales con la federación o Estado central. La responsabilidad estatal frente a la Unión Europea ha tenido también su influencia en la configuración de estos mecanismos, como hemos visto en el caso italiano.

Pero lo que, a nuestro modo de ver, más se evidencia con el repaso a los distintos ordenamientos estudiados desde la perspectiva de la experiencia española es la insuficiencia de estos mecanismos — por sí solos- para la consecución de la paz federal en casos de especial gravedad, en los que se producen incumplimientos reiterados por uno o varios entes territoriales. Pues, pese a ofrecer soluciones coyunturales a problemas puntuales de desajuste territorial, pueden revelarse inútiles frente a una voluntad decidida de ruptura. A este respecto, resulta interesante el ordenamiento italiano, en el que, como hemos visto, se arbitran distintas posibilidades de intervención estatal sustitutiva para atajar incumplimientos o lesiones del interés general menores antes de que estos se reiteren o se agraven y hagan necesarias medidas más drásticas como la de disolver el Consejo Regional y deponer al presidente de la Junta del Gobierno. Otro modo de evitar las situaciones límite podría consistir en adoptar medidas de prevención y solución de conflictos que posibiliten la implicación y el acuerdo entre todas las partes afectadas, como las arbitradas en el ordenamiento belga, aunque siempre sobre la base irrenunciable de la lealtad federal —o podríamos decir, simplemente, constitucional- y con los necesarios ajustes. 


\section{Bibliografía}

Barbera, A. y Fusaro, C. (2016). Corso di diritto costituzionale. Bolonia: Il Mulino.

Blanco de Morais, C. (1999). Portogallo: requiem per il regionalismo amministrativo. Quaderni costituzionali, 2, 419-421.

Buffoni, L. (2007). La metamorfosi della funzione di controllo nella Repubblica delle Autonomie. Saggio critico sull'art. 120, comma II della Costituzione. Torino: Giappichelli.

Bussjäger, P. (2010). Between Europeanization, unitarism and autonomy. Remarks on the current situation of federalism in Austria. Revista d'estudis autonòmics i federals, 10, 11-39. (2017). El federalismo cooperativo de Austria. En W. Hofmeister, J. Tudela (eds.). Sistemas federales. Una comparación (pp. 172-202). Zaragoza: Fundación Konrad Adenauer; Fundación Giménez Abad.

Cameli, R. (2005). Il potere sostitutivo del difensore civico regionale nei confronti degli enti local. Il Foro amministrativo, 0, 2823-2849.

Cardoen, M. (2011). El sistema constitucional de Bélgica. Revista de Derecho Constitucional Europeo, 15, 223-260.

De Cueto Nogueras, C. (2009). Federalismo y democracia consociacional en la política belga. Teoria y Realidad Constitucional, 24, 545-563. Disponible en: https://doi. org/10.5944/trc.24.2009.6880.

De Leonardis, F. (2009). Il difensore civico nella giurisprudenza del giudice costituzionale e del giudice amministrativo. Il Foro amministrativo, 12, 2971-2983.

De Winter, L. (2005). Federalismo y la sostenibilidad de Bélgica. Zaragoza: Fundación Giménez Abad.

Erk, J. (2004). Austria: A Federation without Federalism. Publius: The Journal of Federalism, 34 (1), 1-20. Disponible en: https://doi.org/10.1093/oxfordjournals.pubjof.a005016.

Fontana, G. (2004). I poteri sostitutivi delle Regioni tra inevitabili forzature ed evitabili incoerenze. Giurisprudenza costituzionale, 609, 406-414.

- (2018). Comentario al artículo 120 de la Constitución Italiana. En F. Clementi y otros (a cura di). La Costituzione italiana, vol. II, parte II (pp. 381-384). Bologna: Il Mulino.

Forster, P. (2000). Eigenständigkeit der Kantone, Vorrang und Einhaltung des Bundesrechts und Bundesgarantien. En Die neue schweizerische Bundesverfassung (pp. 132-149). Fribourg Suisse: Helbing \& Lichtenhahn.

Gambino, S. (a cura di) (2007). Forme di Governo. Milano: Giuffrè.

Gamper, A. (2004). Legislative and Executive Federalism in Austria. Vienna: Braumüller Verlag.

Gerpe, M. y Barceló, M. (coords.) (2006). El federalismo judicial, aproximación a los sistemas judiciales de Estados Unidos, Suiza, Canadá y Alemania. Barcelona: Institut d'Estudis Autonòmics.

Gómez Orfanel, G. (2005). La coerción federal en el derecho comparado. Cuadernos de Derecho Público, 25, 41-60.

Gori, L. (2013). La minaccia di rimozione del Presidente della Regione come nuova frontiera del coordinamento della finanza pubblica? Il decreto legislativo "premi e sanzioni”. Giurisprudenza Costituzionale, 4, 3150-3163.

Häfelin, U. y Haller, W. (2008). Schweizerisches Bundesstaatsrecht. Zürich: Schulthess. 
Lang, A. y Sanna, C. (2005). Federalismo e regionalismo. Milano: Giuffrè.

Le Roy, Y. y Schoenenberger, M. B. (2015). Introduction générale au droit Suisse. Zurich: Schulthess.

López Mira, A. X. (2001). La regionalización en Portugal. Revista de las Cortes Generales, 53, 111-197. Disponible en: https://doi.org/10.33426/rcg/2001/53/748.

Mainardis, C. (2001). I poteri sostitutivi statali: una reforma costituzionale con (poche) luce e (molti) ombre. Le Regioni, 6, 1357-1398.

- (2007). Poteri sostitotivi statali e autonomía amministrativa regionali. Milano: Guiffrè.

Mancini, M. (2016). Lo scioglimento "sanzionatorio" degli organi regionali. Milano: Guiffrè.

Mastromarino, A. (2015). Modificaciones constitucionales en Bélgica. La sixième réforme de l'Etat: un proceso en marcha. Revista d'estudis autonòmics i federals, 22, 64-93.

Miranda, J. (2007). A originalidade e as principais características da Constituição portuguesa. Cuestiones Constitucionales, 15, 253-280. Disponible en: https://doi.org/10.22201/ iij.24484881e.2007.16.5793.

Morana, D. (2018). Comentario al artículo 117.5 de la Constitución Italiana. En F. Clementi y otros (a cura di). La Costituzione italiana, vol. II, parte II (pp. 350-351). Bologna: Il Mulino.

Noguera Fernández, A. (2013). ¿Constitución o Ley Fundamental? acerca de la Constitución portuguesa de 1976. Estudios Constitucionales, 11 (2), 615-638. Disponible en: https:// doi.org/10.4067/S0718-52002013000200016.

Pérez Ayala, A. (2007). Tres décadas de evolución constitucional en Portugal (1976-2006). Revista de Derecho Politico, 70, 65-134. Disponible en: https://doi.org/10.5944/ rdp.70.2007.9029.

Pinelli, C. (2013). In tema di scioglimento e rimozione degli organi regionali. Giurisprudenza costituzionale, 4, 3145-3149.

Rodrigues Canotilho, M. (2010). El sistema constitucional de Portugal. Revista de Derecho Constitucional Europeo, 14, 117-135.

Rodríguez-Patrón, P. (2008). El Consejo de Estados suizo. En J. J. Solozábal (coord.). Repensar el Senado. Estudios sobre su reforma (pp. 347-396). Madrid: Secretaría General del Senado.

(2014). El sistema federal suizo. En J. J. Solozábal (coord.). La reforma federal: España y sus siete espejos (pp. 311-354). Madrid: Biblioteca Nueva.

Scholsem, J. C. (1995). La nueva Constitución belga. Revista del Centro de Estudios Constitucionales, 20, 61-164.

Soares Martinez, P. (1978). Comentários à Constituiçao portuguesa de 1976. Lisboa: Verbo.

Sofia, G. (2006). Controllo sostitutivo sugli atti degli enti locali e difensore civico nella legge della Regione Abruzzo 23 gennaio 2004. Riflessioni. Spunti critici. Regioni e Comunità Locali, 3, 25-41.

Sterpa, A. (2018). Comentario al artículo 126 de la Constitución Italiana. En F. Clementi y otros (a cura di). La Costituzione italiana, vol. II, parte II (pp. 407-412). Bologna: Il Mulino.

Thalmann, U. (2000). Subsidiaritätsprinzip und Kompetenzverteilung. En Die neue schweizerische Bundesverfassung (pp. 149-170). Fribourg Suisse: Helbing \& Lichtenhahn. 
Vernet i Llobet, J. (1996). El Bundesrat austríaco. En El Senado, Cámara de representación territorial, III Jornadas de la Asociación Española de Letrados de Parlamentos (pp. 129-138). Madrid: Tecnos.

Veronesi, G. (2002). Il regime dei poteri sostitutivi alla luce del nuevo art. 120, comma 2 de la Costituzione. Le Istituzione del Federalismo, 5, 733-758. 